OPEN ACCESS

Edited by:

John A. Kellum,

University of Pittsburgh, United States

Reviewed by:

Pravin C. Singhal,

North Shore Long Island Jewish Health System, United States

Michael Dürr

Charité-Universitätsmedizin

Berlin, Germany

${ }^{*}$ Correspondence:

Kent Doi

kdoi-tky@umin.ac.jp

Specialty section:

This article was submitted to Nephrology

a section of the journal

Frontiers in Medicine

Received: 23 May 2020 Accepted: 12 October 2020 Published: 20 November 2020

Citation:

Maeda A, Hayase N and Doi K (2020) Acute Kidney Injury Induces Innate Immune Response and Neutrophil Activation in the Lung.

Front. Med. 7:565010.

doi: 10.3389/fmed.2020.565010

\section{Acute Kidney Injury Induces Innate Immune Response and Neutrophil Activation in the Lung}

\author{
Akinori Maeda, Naoki Hayase and Kent Doi* \\ Department of Acute Medicine, The University of Tokyo Hospital, Tokyo, Japan
}

Complication in acute kidney injury (AKI) is significantly associated with developing acute respiratory failure (ARF), while ARF is one of the most important risks for AKI. These data suggest AKI and ARF may synergistically worsen the outcomes of critically ill patients and these organ injuries may not occur independently. Organ crosstalk between the kidney and the lung has been investigated by using animal models so far. This review will focus on innate immune response and neutrophil activation among the mechanisms that contribute to this organ crosstalk. AKI increased the blood level of an inflammatory mediator in high-mobility group box 1 , which induces an innate immune reaction via toll-like receptor 4 . The remarkable infiltration of neutrophils to the lung was observed in animal AKI models. IL-6 and IL-8 have been demonstrated to contribute to pulmonary neutrophil activation in AKI. In addition, the formation of a neutrophil extracellular trap was also observed in the lung after the exposure of renal ischemia reperfusion in the animal model. Further investigation is necessary to determine whether targeting innate immune response and neutrophil activation will be useful for developing new therapeutics that could improve multiple organ failure in critically ill patients.

\section{Keywords: neutrophil, IL-6, high mobility group box 1, toll-like receptor, neutrophil extracellular trap}

\section{INTRODUCTION}

Acute kidney injury (AKI) is a common complication in critically ill patients treated in the intensive care unit (ICU). Reportedly, AKI occurs in $~ 30-60 \%$ of patients admitted to the ICU and is associated with significantly poor outcomes including morbidity and mortality (1). ICU patients with AKI will be complicated by a broad range of other organ injuries including heart failure, respiratory failure, liver injury, and immunological abnormalities. Many animal studies demonstrated that AKI induces cardiac, lung, liver, brain, and splenic injury (2). Therefore, AKI should be considered as a systemic disease that can have significant impacts on distant organs.

Though the primary roles are different, lung and kidney functions are intimately related regarding the maintenance of homeostasis. The blood acid-base balance is regulated by carboxy dioxide excretion by the lung and bicarbonate reabsorption by the kidney. A compensative mechanism will activate when one organ fails to keep these levels within a normal range by the other organ. Thus, respiratory complication in AKI patients is particularly important. Clinical studies revealed AKI patients were twice as likely to require invasive mechanical ventilation (3). On the other hand, acute respiratory failure (ARF)/acute respiratory distress syndrome (ARDS) patients, especially those who require invasive mechanical ventilation, are at high risk for developing AKI $(4,5)$. 
In this review, we provide a brief overview regarding (1) the clinical data on AKI and ARF/ARDS and (2) the potential mechanisms by which AKI leads to lung injury. Recently identified mechanisms of the innate immune system including toll-like receptors (TLRs) and damage-associated molecular patterns (DAMPs) were evaluated in the kidney-lung crosstalk using animal models. Neutrophil extracellular traps (NETs) was identified as another player in the innate immune response. NETs were also demonstrated to contribute to AKI-induced lung injury.

\section{CLINICALLY REPORTED ASSOCIATIONS BETWEEN AKI AND ARF/ARDS}

Many clinical studies suggested associations between AKI and ARF/ARDS in critically ill patients. AKI often occurs in ARF/ARDS patients, while ARF/ARDS is often observed in AKI patients. First, clinical data about AKI complication in ARF/ARDS are described below. The secondary analysis of a randomized control trial conducted by the ARDS network reported AKI occurred in $\sim 25 \%$ of ARDS patients. The mortality rate of AKI patients was significantly higher than the non-AKI patients (6). Another study reported that AKI was observed in $\sim 35 \%$ of hospitalized patients with communityacquired pneumonia. AKI was significantly associated with the requirement of mechanical ventilation (MV) and mortality (4). A meta-analysis including 31 studies reported a significantly high AKI occurrence when the patients were mechanically ventilated (5). These data suggest that AKI is a common complication and a risk factor for poor outcomes of ARF/ARDS.

Second, ARF/ARDS complication in AKI is described below. Severe ARF requiring MV was observed in more than $70 \%$ of AKI patients in a multinational, multicenter prospective observational study. MV requirement was significantly associated with higher mortality (7). Dialysis-requiring AKI (AKI-D) is the most severe form of AKI (defined as AKI stage 3 by the KDIGO criteria). A small retrospective study reported that $44 \%$ of AKI-D patients treated in an ICU developed ARDS (8). Therefore, ARF/ARDS is a common complication and a risk factor for poor outcomes of AKI.

Third, AKI and ARF/ARDS are organ failures that can be simultaneously complicated in a critically ill patient. An observational study conducted in 18 French ICUs reported ARDS occurrence as $23 \%$, while AKI occurrence was at $31 \%$. Hospital mortality was $14 \%$ in this population and it increased to $42 \%$ in patients with both AKI and ARDS (9). In a large cohort of 200,000 admissions for subarachnoid hemorrhage (SAH) from the Nationwide Inpatient Sample database, the incidence of ARDS in SAH patients was $\sim 35 \%$ and renal dysfunction predicted ARDS development (10). A nationwide study including $\sim 7$ million patients with acute ischemic stroke showed AKI patients had a significantly higher risk of requiring MV than non-AKI (11). As described above, both AKI and ARF/ARDS are common organ failures in critically ill patients with other etiologies such as sepsis and the coexistence of these issues will exacerbate the outcomes. However, it should be noted that these
TABLE 1 | Pathophysiological mechanisms of respiratory failure in AKI.

\begin{tabular}{ll}
\hline Non-inflammatory & Fluid overload \\
& Cardiac dysfunction \\
Inflammatory & and IL-8) \\
& Neutrophil activation \\
& Pulmonary endothelial apoptosis \\
& Oxidative stress
\end{tabular}

clinical observational studies do not indicate causal relationships but only associations between these two types of organ failures.

\section{POSSIBLE MECHANISM OF ORGAN CROSSTALK BETWEEN THE KIDNEY AND THE LUNG}

The pathophysiological mechanisms of respiratory failure in patients with AKI can be categorized into inflammatory and non-inflammatory mechanisms (Table 1). Non-inflammatory mechanisms include fluid overload and cardiac dysfunction. Rapid progression of lung edema and fluid overload, which do not respond to diuretics, are frequently observed in AKI patients. Although inflammatory mechanisms are not well-recognized in basic clinical research, using animal models demonstrated that increased inflammatory mediators in AKI play a crucial role in lung injury.

Rabb and colleagues first demonstrated increased inflammatory gene expressions in the lung after exposure of renal ischemia reperfusion injury by using microarray analysis (12). Faubel et al. (13) demonstrated the role of IL-6 in AKIinduced lung injury with IL-6 knockout mouse experiments. The reduced clearance of inflammatory mediators including IL-6 in AKI seemed to contribute to lung injury. Furthermore, they reported that IL-6-induced expression of the chemokine CXCL1 in the lung was responsible for recruiting neutrophil into the lung induced by AKI (14). These findings suggest that circulating IL-6 is a pathogenic mediator of lung injury in AKI. IL-10, an anti-inflammatory cytokine, was shown to be produced by spleen CD4-positive T cells in response to IL-6 in AKI. The induction of IL-10 expression by IL- 6 appeared to contribute to the suppression of lung injury induced by AKI as a counterbalance (15). Other mediators and inflammatory cells were also reported as possible contributors to lung injury induced by AKI (Table 2).

Although these studies suggested that the induction of an inflammatory reaction by AKI is involved in lung injury, other studies demonstrated AKI suppressed inflammatory reactions and subsequently worsened pulmonary infection. Neutrophil function against pneumonia was evaluated in the model of bacterial pneumonia in mice complicated with AKI by folic acid administration or glycerol injection (rhabdomyolysis) (16). Neutrophil migration was rather weakened and the pneumonia was exacerbated in AKI animals. Another study reported that the neutrophil migration ability at microcirculation of the cremaster muscle was decreased in AKI mice (17). AKI-induced neutrophil 
TABLE 2 | Mediators of lung injury in AKI.

\begin{tabular}{|c|c|}
\hline \multirow[t]{7}{*}{ IL-6 } & Serum IL-6 can be used as a predictor of AKI \\
\hline & $\begin{array}{l}\text { Serum IL-6 level elevates in the very early stage of } \\
\text { AKI }\end{array}$ \\
\hline & $\begin{array}{l}\text { Higher level of serum IL-6 is associated with the } \\
\text { prolonged mechanical ventilation in patients with } \\
\text { AKI }\end{array}$ \\
\hline & $\begin{array}{l}\text { IL-6 antibody-treated mice exhibit less lung } \\
\text { inflammation and fewer capillary leaks }\end{array}$ \\
\hline & $\begin{array}{l}\text { IL-6 deficient mice exhibit less lung inflammation } \\
\text { and fewer capillary leaks }\end{array}$ \\
\hline & $\begin{array}{l}\text { Intravenous IL-6 injection to IL-6 deficient mice } \\
\text { restores lung inflammation }\end{array}$ \\
\hline & Circulating IL-6 causes lung inflammation in AKI \\
\hline \multirow[t]{5}{*}{ IL-8 } & $\begin{array}{l}\text { Serum IL-8 levels elevate in the very early stage of } \\
\text { AKI }\end{array}$ \\
\hline & $\begin{array}{l}\text { Higher level of serum IL-8 is associated with the } \\
\text { prolonged mechanical ventilation in patients with } \\
\text { AKI }\end{array}$ \\
\hline & $\begin{array}{l}\text { Higher level of serum IL- } 8 \text { is a predictor of increased } \\
\text { mortality in patients with AKI }\end{array}$ \\
\hline & IL-8 antibody-treated mice exhibit less lung injury \\
\hline & IL-8 deficient mice exhibit less lung injury \\
\hline \multirow[t]{4}{*}{$\begin{array}{l}\text { TNFR1 + caspase-3- } \\
\text { mediated apoptosis }\end{array}$} & $\begin{array}{l}\text { Circulating TNF and caspase- } 3 \text { increase endothelial } \\
\text { apoptosis and lead to non-cardiogenic pulmonary } \\
\text { edema }\end{array}$ \\
\hline & $\begin{array}{l}\text { Pan-caspase inhibition reduces pulmonary edema } \\
\text { after AKI }\end{array}$ \\
\hline & $\begin{array}{l}\text { TNF inhibition reduces apoptosis and pulmonary } \\
\text { edema after AKI }\end{array}$ \\
\hline & $\begin{array}{l}\text { TNFR1 deficient mice exhibit less lung caspase-3 } \\
\text { and lung apoptosis after AKI }\end{array}$ \\
\hline \multirow[t]{3}{*}{ T cells } & $\begin{array}{l}\text { T cells participate in lung apoptosis via caspase- } 3 \\
\text { and lead to non-cardiogenic pulmonary edema }\end{array}$ \\
\hline & $\mathrm{T}$ cells are recruited to the lung within $24 \mathrm{~h}$ after $\mathrm{AKI}$ \\
\hline & $\begin{array}{l}\text { T cell deficient mice exhibit less caspase- } 3 \text { and less } \\
\text { pulmonary edema }\end{array}$ \\
\hline
\end{tabular}

TNFR1, tumor necrosis factor receptor 1.

dysfunction might be caused by an adipokine resistin (18). Resistin is known as a uremic toxin and pro-inflammatory cytokine secreted by monocytes, neutrophils, and epithelial cells (19). It should be noted septic patients in the ICU showed higher blood levels of resistin than non-septic patients (20).

Taken together, increased humoral mediators by reduced clearance and increased expression in AKI seem to contribute to lung injury. On the other hand, few studies revealed the mechanisms of the opposite direction of crosstalk, i.e., ARF/ARDS-induced kidney injury. Slutsky et al. (21) reported increased epithelial cell apoptosis in the kidney in a rabbit ARDS model followed by mechanical ventilation with injurious ventilatory strategies (high tidal volume and high PEEP). An infiltration of lymphocytes was seen in the renal cortex in a pig ARDS model with mechanical ventilation (22). On the other hand, another study found no renal structural and functional alterations in a canine ARDS model when hemodynamics and arterial blood gas tensions are carefully controlled (23), indicating the possible role of a non-inflammatory mechanism for kidney injury in ARDS. Further investigation is necessary for whether inflammatory mediators play any role in ARF/ARDSinduced kidney injury.

\section{INNATE IMMUNE RESPONSE AND NEUTROPHIL ACTIVATION}

Neutrophil infiltration is a major finding in lung injury induced by AKI. A remarkable neutrophil infiltration in the lung together with increased neutrophil elastase (NE) activity in blood and lung tissues were observed in a mouse AKI model and specific NE inhibitor reduced lung injury (24). Toll-like receptors (TLRs) are pattern recognition receptors that recognize pathogenassociated molecular patterns (PAMPs) and damage-associated molecular patterns (DAMPs). TLRs play an important role in innate immunity, and are involved not only in the defense against infection but also in various pathological conditions. An inflammatory mediator, high-mobility group protein B1 (HMGB1) is one of the DAMP TLR4 ligands. We revealed that TLR4 loss-of-function mutant mice $(\mathrm{C} 3 \mathrm{H} / \mathrm{HeJ})$ were resistant to lung injury caused by AKI (25). Although blood levels of HMGB1 increased in AKI regardless of TLR4 mutation, antiHMGB1 neutralizing antibody treatment reduced lung injury only in the wild-type mice, indicating the organ protecting effect was mediated by the HMGB1-TLR4 pathway.

Extracellular histones induce cytotoxicity as DAMPs trigger the inflammatory cascade via toll-like receptors. Extracellular histones are released from neutrophils during the formation of neutrophil extracellular traps (NETs), that comprise DNA studded with histones and proteases, including neutrophil elastases (26). Extracellular histones and NETs were reported to associate with the pathogenesis of acute lung injury in an animal AKI model. Nakazawa et al. (27) showed that the induction of necrosis in renal tubular epithelial cells in vitro caused by hypoxia stimulated neutrophils to form NETs by extracellularly released histones. In a mouse intestinal ischemia-reperfusion model, extracellular histone accumulation and NETs formation were observed in the liver rather than the intestine (28). Extracellular histones derived from the intestinal tract were considered to transported to the liver via the portal system. In the mouse renal ischemia-reperfusion injury model, elevated extracellular histones in blood and NETs formation in the lung was observed (27). Human recombinant thrombomodulin (rTM) reportedly trap extracellular histones in vitro. Although no renal protection by rTM was observed in the renal ischemia-reperfusion model, significant improvement of lung injury together with NTEs accumulation induced by AKI was observed in rTM-treated animals (29).

These findings above suggest that extracellular histones and NETs formation might be responsible for AKI-induced lung injury, although other pathways of inflammatory mediators such as IL-6 also contribute to AKI-induced lung injury. For the development of new therapeutics against organ crosstalk between the kidney and lung, targeting multiple pathways will be necessary. In addition, extracellular histones and NETs formation 
have not been sufficiently evaluated in human ARDS (30) and no clinical study examined this pathway in terms of lung-kidney crosstalk. Further evaluation of these pathways in a clinical setting is absolutely required.

\section{POSSIBLE ORGAN CROSSTALK BETWEEN THE KIDNEY AND THE LUNG IN COVID-19}

The novel coronavirus disease (COVID-19) caused by severe acute respiratory syndrome coronavirus 2 (SARS-CoV-2) was first reported in Wuhan in December 2019, which has spread around the world. SARS-CoV-2 dominantly affects the respiratory system and recent clinical studies reported AKI as a significant comorbidity in COVID-19 (31). The cell surface protein, angiotensin-converting enzyme 2 (ACE2 ), which is used by the virus as an entry receptor, is abundantly expressed not only in lung epithelial cells but in renal tubular epithelial cells (32), indicating SARS-CoV-2 could directly infect the kidneys. We recently observed that the urinary neutrophil gelatinase-associated lipocalin (NGAL) level at ICU admission was significantly elevated among patients who developed AKI. Furthermore, urinary NGAL was correlated with length of mechanical ventilation use (33). Because urinary NGAL is expected to reflect renal tubular epithelial cell damage, elevated NGAL might reflect the burden of viral insult of renal damage directly and lung injury indirectly.

\section{DISCUSSION}

Multiple organ failure frequently observed in critically ill patients was previously considered as the "sum" of each organ failure. The sequential organ failure assessment (SOFA) score, which is widely used for evaluating the severity of ICU patients, is calculated by summing up each organ injury score. No consideration for organ crosstalk can be found in these scoring systems. Several clinical studies demonstrated possible organ crosstalk in ICU patients by applying network analysis $(34,35)$. As described above, basic research revealed several different pathways that contributed to organ crosstalk related to AKI (36). Unfortunately, no clinical evidence is available for organ crosstalk demonstrated by animal

\section{REFERENCES}

1. Ronco C, Bellomo R, Kellum JA. Acute kidney injury. Lancet. (2019) 394:1949-64. doi: 10.1016/S0140-6736(19)32563-2

2. Faubel S, Edelstein CL. Mechanisms and mediators of lung injury after acute kidney injury. Nat Rev Nephrol. (2016) 12:48-60. doi: 10.1038/nrneph.2015.158

3. Vieira JM, Jr, Castro I, Curvello-Neto A, Demarzo S, Caruso P, Pastore $\mathrm{L}$ Jr, et al. Effect of acute kidney injury on weaning from mechanical ventilation in critically ill patients. Crit Care Med. (2007) 35:18491. doi: 10.1097/01.CCM.0000249828.81705.65

4. Murugan R, Karajala-Subramanyam V, Lee M, Yende S, Kong L, Carter M, et al. Acute kidney injury in non-severe pneumonia is associated with an increased immune response and lower survival. Kidney Int. (2010) 77:52735. doi: 10.1038/ki.2009.502 experiments. Future studies that could clarify the significance of organ crosstalk in the clinical setting is necessary to develop a novel therapeutic strategy that targets currently unrecognized organ crosstalk in critically ill patients.

This review covers kidney-lung crosstalk mostly regarding lung injury caused by AKI. The opposite pathological mechanism in which ARF/ARDS causes AKI should also be considered. As described above, only a limited number of basic studies reported possible mechanisms in animal experiments. In clinical studies, ARF/ARDS caused a systemic release of pro-inflammatory mediators (plasminogen activator inhibitor-1, IL-6, and soluble TNF receptors-1 and 2), which could induce or worsen AKI (6). AKI can be caused by a reduction in renal blood flow caused by hypoxemia or hypercapnia, and a decreased glomerular filtration rate due to the elevation of central venous pressure (renal congestion). In patients with ARF/ARDS, these mechanisms could initiate or aggravate AKI and cause those patients to fall into a vicious cycle (37).

Mechanical ventilation-induced lung injury has been investigated so far. Low tidal ventilation strategy against ARDS is recommended based on evidence obtained by both basic and clinical studies (38). Does MV have any significant impacts on the kidney injury? Excessive tidal volume leads to proinflammatory mediator release. High positive end-expiratory pressure can cause elevated intrathoracic pressure and systemic venous pressure, leading to a reduced net glomerular filtration rate. Lung protective ventilation based on the volume-pressure curve can achieve lower levels of TNF- $\alpha$, IL-1b, IL-6, and IL-8 in bronchoalveolar lavage fluid with a lower incidence of AKI in the clinical setting (39).

\section{AUTHOR CONTRIBUTIONS}

$\mathrm{AM}, \mathrm{NH}$, and $\mathrm{KD}$ contributed to the writing of the manuscript and approved the final version of the manuscript.

\section{FUNDING}

This study was partly supported by JSPS KAKENHI Grant Number 19K18346 (NH). meta-analysis. Crit Care. (2013) 17:R98. doi: 10.1186/cc12743

6. Liu KD, Glidden DV, Eisner MD, Parsons PE, Ware LB, Wheeler A, et al. Predictive and pathogenetic value of plasma biomarkers for acute kidney injury in patients with acute lung injury. Crit Care Med. (2007) 35:275561. doi: 10.1097/00003246-200712000-00013

7. Uchino S, Kellum JA, Bellomo R, Doig GS, Morimatsu H, Morgera S, et al. Acute renal failure in critically ill patients: a multinational, multicenter study. JAMA. (2005) 294:813-8. doi: 10.1001/jama.294.7.813

8. Franzen D, Rupprecht C, Hauri D, Bleisch JA, Staubli M, Puhan MA. Predicting outcomes in critically ill patients with acute kidney injury undergoing intermittent hemodialysis-a retrospective cohort analysis. Int $J$ Artif Organs. (2010) 33:15-21. doi: 10.1177/0391398810033 00103 
9. Darmon M, Clec'h C, Adrie C, Argaud L, Allaouchiche B, Azoulay E, et al. Acute respiratory distress syndrome and risk of AKI among critically ill patients. Clin J Am Soc Nephrol. (2014) 9:1347-53. doi: 10.2215/CJN.08300813

10. Veeravagu A, Chen YR, Ludwig C, Rincon F, Maltenfort M, Jallo J, et al. Acute lung injury in patients with subarachnoid hemorrhage: a nationwide inpatient sample study. World Neurosurg. (2014) 82:e23541. doi: 10.1016/j.wneu.2014.02.030

11. Saeed F, Adil MM, Khursheed F, Daimee UA, Branch LA, Jr, Vidal GA, et al. Acute renal failure is associated with higher death and disability in patients with acute ischemic stroke: analysis of nationwide inpatient sample. Stroke. (2014) 45:1478-80. doi: 10.1161/STROKEAHA.114.004672

12. Grigoryev DN, Liu M, Hassoun HT, Cheadle C, Barnes KC, Rabb H. The local and systemic inflammatory transcriptome after acute kidney injury. J Am Soc Nephrol. (2008) 19:547-58. doi: 10.1681/ASN.2007040469

13. Klein CL, Hoke TS, Fang WF, Altmann CJ, Douglas IS, Faubel S. Interleukin6 mediates lung injury following ischemic acute kidney injury or bilateral nephrectomy. Kidney Int. (2008) 74:901-9. doi: 10.1038/ki.2008.314

14. Ahuja N, Andres-Hernando A, Altmann C, Bhargava R, Bacalja J, Webb RG, et al. Circulating IL-6 mediates lung injury via CXCL1 production after acute kidney injury in mice. Am J Physiol Renal Physiol. (2012) 303:F86472. doi: 10.1152/ajprenal.00025.2012

15. Andres-Hernando A, Okamura K, Bhargava R, Kiekhaefer CM, Soranno D, Kirkbride-Romeo LA, et al. Circulating IL-6 upregulates IL-10 production in splenic CD4(+) $\mathrm{T}$ cells and limits acute kidney injury-induced lung inflammation. Kidney Int. (2017) 91:1057-69. doi: 10.1016/j.kint.2016.12.014

16. Singbartl K, Bishop JV, Wen X, Murugan R, Chandra S, Filippi MD, et al. Differential effects of kidney-lung cross-talk during acute kidney injury and bacterial pneumonia. Kidney Int. (2011) 80:633-44. doi: 10.1038/ki.2011.201

17. Rossaint J, Spelten O, Kassens N, Mueller H, Van Aken HK, Singbartl K, et al. Acute loss of renal function attenuates slow leukocyte rolling and transmigration by interfering with intracellular signaling. Kidney Int. (2011) 80:493-503. doi: 10.1038/ki.2011.125

18. Singbartl K, Miller L, Ruiz-Velasco V, Kellum JA. Reversal of acute kidney injury-induced neutrophil dysfunction: a critical role for resistin. Crit Care Med. (2016) 44:e492-501. doi: 10.1097/CCM.0000000000001472

19. Cohen G, Horl WH. Resistin as a cardiovascular and atherosclerotic risk factor and uremic toxin. Semin Dial. (2009) 22:3737. doi: 10.1111/j.1525-139X.2009.00583.x

20. Koch A, Gressner OA, Sanson E, Tacke F, Trautwein C. Serum resistin levels in critically ill patients are associated with inflammation, organ dysfunction and metabolism and may predict survival of non-septic patients. Crit Care. (2009) 13:R95. doi: 10.1186/cc7925

21. Imai Y, Parodo J, Kajikawa O, de Perrot M, Fischer S, Edwards V, et al. Injurious mechanical ventilation and end-organ epithelial cell apoptosis and organ dysfunction in an experimental model of acute respiratory distress syndrome. JAMA. (2003) 289:2104-12. doi: 10.1001/jama.289.16.2104

22. Heuer JF, Sauter P, Pelosi P, Herrmann P, Bruck W, Perske C, et al. Effects of pulmonary acid aspiration on the lungs and extra-pulmonary organs: a randomized study in pigs. Crit Care. (2012) 16:R35. doi: 10.1186/cc11214

23. Hoag JB, Liu M, Easley RB, Britos-Bray MF, Kesari P, Hassoun H, et al. Effects of acid aspiration-induced acute lung injury on kidney function. Am J Physiol Renal Physiol. (2008) 294:F900-8. doi: 10.1152/ajprenal.00357.2007

24. Ishii $\mathrm{T}$, Doi $\mathrm{K}$, Okamoto $\mathrm{K}$, Imamura $\mathrm{M}$, Dohi $\mathrm{M}$, Yamamoto $\mathrm{K}$, et al. Neutrophil elastase contributes to acute lung injury induced by bilateral nephrectomy. Am J Pathol. (2010) 177:166573. doi: 10.2353/ajpath.2010.090793

25. Doi K, Ishizu T, Tsukamoto-Sumida M, Hiruma T, Yamashita T, Ogasawara $\mathrm{E}$, et al. The high-mobility group protein B1-Toll-like receptor 4 pathway contributes to the acute lung injury induced by bilateral nephrectomy. Kidney Int. (2014) 86:316-26. doi: 10.1038/ki.2014.62

26. Brinkmann V, Reichard U, Goosmann C, Fauler B, Uhlemann Y, Weiss DS, et al. Neutrophil extracellular traps kill bacteria. Science. (2004) 303:15325. doi: 10.1126/science. 1092385
27. Nakazawa D, Kumar SV, Marschner J, Desai J, Holderied A, Rath L, et al. Histones and neutrophil extracellular traps enhance tubular necrosis and remote organ injury in ischemic AKI. J Am Soc Nephrol. (2017) 28:175368. doi: 10.1681/ASN.2016080925

28. Hayase N, Doi K, Hiruma T, Matsuura R, Hamasaki Y, Noiri E, et al. Recombinant thrombomodulin on neutrophil extracellular traps in murine intestinal ischemia-reperfusion. Anesthesiology. (2019) 131:86682. doi: 10.1097/ALN.0000000000002898

29. Hayase N, Doi K, Hiruma T, Matsuura R, Hamasaki Y, Noiri E, et al. Recombinant thrombomodulin prevents acute lung injury induced by renal ischemia-reperfusion injury. Sci Rep. (2020) 10:289. doi: 10.1038/s41598-019-57205-0

30. Bendib I, de Chaisemartin L, Mekontso Dessap A, Chollet-Martin S, de Prost N. Understanding the role of neutrophil extracellular traps in patients with severe pneumonia and ARDS. Chest. (2019) 156:127880. doi: 10.1016/j.chest.2019.08.2179

31. Fu EL, Janse RJ, de Jong Y, van der Endt VHW, Milders J, van der Willik $\mathrm{EM}$, et al. Acute kidney injury and kidney replacement therapy in COVID19: a systematic review and meta-analysis. Clin Kidney J. (2020) 13:55063. doi: $10.1093 / \mathrm{ckj} / \mathrm{sfaa} 160$

32. Hamming I, Timens W, Bulthuis ML, Lely AT, Navis G, van Goor H. Tissue distribution of ACE2 protein, the functional receptor for SARS coronavirus. A first step in understanding SARS pathogenesis. J Pathol. (2004) 203:6317. doi: 10.1002 /path.1570

33. Komaru Y, Doi K, Nangaku M. Urinary neutrophil gelatinaseassociated lipocalin in critically ill patients with coronavirus disease 2019. Crit Care Explor. (2020) 2:e0181. doi: 10.1097/CCE.00000000000 00181

34. Asada T, Aoki Y, Sugiyama T, Yamamoto M, Ishii T, Kitsuta Y, et al. Organ system network disruption in nonsurvivors of critically ill patients. Crit Care Med. (2016) 44:83-90. doi: 10.1097/CCM.0000000000 001354

35. Asada T, Doi K, Inokuchi R, Hayase N, Yamamoto $M$, Morimura N. Organ system network analysis and biological stability in critically ill patients. Crit Care. (2019) 23:83. doi: 10.1186/s13054-0192376-y

36. Doi K, Rabb H. Impact of acute kidney injury on distant organ function: recent findings and potential therapeutic targets. Kidney Int. (2016) 89:55564. doi: 10.1016/j.kint.2015.11.019

37. Schefold JC, Filippatos G, Hasenfuss G, Anker SD, von Haehling S. Heart failure and kidney dysfunction: epidemiology, mechanisms and management. Nat Rev Nephrol. (2016) 12:610-23. doi: 10.1038/nrneph. 2016.113

38. Acute Respiratory Distress Syndrome Network, Brower RG, Matthay MA, Morris A, Schoenfeld D, Thompson BT. Ventilation with lower tidal volumes as compared with traditional tidal volumes for acute lung injury and the acute respiratory distress syndrome. N Eng J Med. (2000) 342:13018. doi: 10.1056/NEJM200005043421801

39. Ranieri VM, Suter PM, Tortorella C, De Tullio R, Dayer JM, Brienza A, et al. Effect of mechanical ventilation on inflammatory mediators in patients with acute respiratory distress syndrome: a randomized controlled trial. JAMA. (1999) 282:54-61. doi: 10.1001/jama.282.1.54

Conflict of Interest: The authors declare that the research was conducted in the absence of any commercial or financial relationships that could be construed as a potential conflict of interest.

Copyright (C) 2020 Maeda, Hayase and Doi. This is an open-access article distributed under the terms of the Creative Commons Attribution License (CC BY). The use, distribution or reproduction in other forums is permitted, provided the original author(s) and the copyright owner(s) are credited and that the original publication in this journal is cited, in accordance with accepted academic practice. No use, distribution or reproduction is permitted which does not comply with these terms. 